\title{
TUTELA DE EVIDÊNCIA: \\ APLICABILIDADE E CASUÍSTICA NO DIREITO PROCESSUAL ELEITORAL
}

\author{
Evidence Injunction: applicability and casuistry in electoral procedural law
}

Fernando Vieira Luiz

Rafael Covolan Pontin

Marina de Oliveira de Vasconcellos Luiz

Resumo: O presente trabalho tem por objetivo analisar a aplicabilidade da tutela de evidência no direito processual eleitoral e verificar utilização do instituto pelas Cortes Eleitorais, com ênfase no Tribunal Superior Eleitoral. Para tanto, expõe o sistema de tutela provisória contido no Código de Processo Civil, discorrendo sobre os requisitos e hipóteses de cabimento da tutela de evidência. Após, descreve a atuação da Justiça Especializada no que toca ao uso desta técnica processual que se destina à melhor distribuição do ônus do tempo no processo. Por fim, conclui que o emprego da tutela de evidência no processo eleitoral é possível no aspecto teórico e importante na prática jurídica como forma de regular de forma equânime o ônus do tempo em situações de quase certeza, dispensando o requisito da urgência.

Palavras-chave: Tutela de evidência. Tutela provisória. Processo eleitoral.

\begin{abstract}
This study analyzes the applicability of evident injunctions in electoral procedural law and verifies its use by the Electoral Courts, emphasizing the Superior Electoral Court. This article exposes the system of provisional injunctions contained in the Code of Civil Procedure, and discusses the requirements and hypotheses of the evident injunctions. The role of the Specialized Justice is discussed with regard to the use of this procedural technique that is intended to better distribute the burden of time in the process. We conclude that the use of evident injunctions in the electoral process is theoretically possible and important in legal practice to regulate the burden of time equitably, dispensing the requirement of urgency.
\end{abstract}

Keywords: Evident injunctions. Provisional injunctions. Electoral process.

Artigo recebido em 7 out. 2020 e aprovado em 5 nov. 2020. 


\section{Introdução}

O Direito Eleitoral persegue, dentre outros fins, a garantia do adequado processo de escolha de governantes e legisladores. Para tanto, prevê prazos processuais notadamente menores se comparados às normas que regem outros procedimentos. Mesmo assim, não é incomum que se demande proteções a posições jurídicas por tutelas provisórias, sobretudo quando a demora na solução final da demanda exija intervenção judicial anterior. Caberia, para esses casos, a utilização do instrumento de redistribuição do ônus do tempo no processo, a tutela de evidência? É essa pergunta que se pretende responder no presente trabalho.

Em revisão bibliográfica sobre o tema, e revisitando-se a legislação, propõe-se estabelecer breves distinções entre as espécies de tutela provisória previstas no direito processual civil, além de examinar os requisitos e as hipóteses de cabimento da tutela de evidências, e sua aplicabilidade no direito processual eleitoral.

Após isso, com pesquisa nos precedentes jurisprudenciais de todas as Cortes Regionais e também no Tribunal Superior Eleitoral, quer-se identificar a casuística em que houve aplicação da tutela de evidência, a fim de estabelecer o modo de aplicação prática desse instituto no campo eleitoral.

\section{Previsão das tutelas provisórias no CPC}

As tutelas provisórias têm como função primaz a distribuição isonômica do ônus temporal no processo. Se uma parte necessita de proteção jurisdicional imediata, sob pena de ver frustrado seu direito quando da futura prestação da tutela jurisdicional, ou possui um direito patente, evidentemente demonstrado, não é adequado que tenha que suportar a demora processual. Tentando equalizar tal situação, o ordenamento jurídico prevê a possibilidade de concessão de tutelas provisórias ${ }^{1}$.

${ }^{1}$ THEODORO JÚNIOR, Humberto. Curso de Direito Processual Civil. 58 ed. Rio de Janeiro: Forense, 2017, p. 778. "O ônus do tempo, às vezes, recai precisamente sobre aquele que se apresenta, perante o juízo, como quem se acha na condição de vantagem que afinal virá a merecer a tutela jurisdicional. Estabelece-se, em quadras como esta, uma situação injusta, em que a demora do processo reverte-se em vantagem para o litigante que, no enfoque atual, não é merecedor da tutela jurisdicional. Criam-se, então, técnicas de sumarização, para que o custo da duração do processo seja melhor distribuído, e não mais continue a recair sobre quem aparenta, no momento, ser o merecedor da tutela da Justiça" 
As tutelas provisórias têm seu regramento geral previsto no Código de Processo Civil, em seus arts. 294 e 311, dividindo os provimentos em "tutela de urgência" (art. 300 a 310) e tutela de evidência (art. 311), além de trazer disposições gerais aplicáveis a ambos os instrumentos (arts. 294 a 299).

\subsection{Breve exposição da tutela de urgência}

O presente trabalho tem foco na tutela de evidência e sua aplicabilidade no direito processual eleitoral. Mesmo assim, é indispensável que se façam breves notas sobre sua coirmã, a tutela de urgência, notadamente para esclarecer a diferenciação de ambas.

A tutela de urgência é calcada no afastamento do risco que o provimento jurisdicional pode sofrer com a demora processual ou do dano irreparável ou de difícil reparação a que a parte está exposta. Visa, assim, garantir que o interessado obtenha, efetivamente, seu direito ao final da demanda ou antecipe essa pretensão. Tal finalidade fica evidente na previsão de seus requisitos (art. 300, caput, do CPC) ${ }^{2}$, que demandam: a) a probabilidade do direito (fumus boni iuris); b) a demonstração do perigo de dano ou do risco ao resultado útil do processo (periculum in mora); e c) a possibilidade de reversão de seus efeitos (art. 300, \ $3^{\circ}$, do CPC) ${ }^{3}$.

Prevê, ainda, o CPC, que a tutela de urgência pode ser concedida em caráter cautelar (assegurar o resultado do processo) ou antecipada (antecipação dos resultados que seriam obtidos ao término do processo), ambas de modo antecedente (feita anteriormente ao pedido de tutela definitiva) ou incidental (realizada dentro do processo em andamento) ${ }^{4}$.

Feitas essa rápida digressão, vamos à tutela de evidência.

\subsection{Tutela de evidência}

O processo demanda seu próprio tempo, que precipuamente serve como meio apto a garantir a resolução justa da lide. O próprio exercício dos direitos fundamentais dos litigantes, como o devido processo legal, contraditório e ampla defesa (do qual decorre o direito à prova, por exemplo),

\footnotetext{
2 "Art. 300. A tutela de urgência será concedida quando houver elementos que evidenciem a probabilidade do direito e o perigo de dano ou o risco ao resultado útil do processo."

3 "S 3 o A tutela de urgência de natureza antecipada não será concedida quando houver perigo de irreversibilidade dos efeitos da decisão."

${ }^{4}$ Art. 294, "Parágrafo único. A tutela provisória de urgência, cautelar ou antecipada, pode ser concedida em caráter antecedente ou incidental."
} 
exige uma dilação no tempo, o que é normal e necessário. Não se justifica o açodamento de direitos fundamentais como os descritos, sequer sob a justificativa de celeridade ou eficiência. Esse inevitável período sempre será desfavorável a alguma das partes.

Objetivando distribuir equitativamente o ônus do tempo no processo, o CPC/15 prevê instrumentos (de tutela provisória), para que não só uma parte, invariavelmente, arque com este efeito temporal ${ }^{5}$. Dentre elas, encontra-se o instituto da tutela da evidência, ou, como indica Amaral, a tutela das posições jurídicas prováveis ${ }^{6}$.

Embora seja albergada pela legislação processual de forma expressa, como um instituto próprio, pela primeira vez, não se trata, por certo, de uma novidade absoluta no ordenamento jurídico brasileiro. Basta lembrar

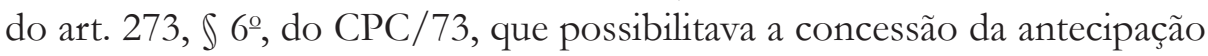
dos efeitos da tutela em relação ao pedido ou parte dele que restasse incontroverso. Igualmente, a situação descrita no art. 311, inciso I, do CPC/15, remete àquela anteriormente verificada no art. 273, II, do CPC/73. A nova codificação, ao separar a tutela de urgência da tutela de evidência, as deixa mais claras aos juristas. Identifica-se mais facilmente, assim, em qual hipótese terá de ser comprovada a urgência da medida, e em qual ela está dispensada, por ser gritante (e, portanto, evidente) em relação ao direito material discutido no processo.

O instituto da tutela de evidência é uma técnica processual que busca afastar daquele que apresenta uma alta probabilidade de êxito o peso da demora da resposta jurisdicional final, ou seja, do ônus do tempo no processo.

${ }^{5}$ FIALHO, Arthur Monteiro Lins; BONIFÁCIO, Artur Cortez. O efetivo acesso ao ju-
diciário e o tempo processual sob a perspectiva da tutela de evidência. Revista de cida-
dania e acesso à justiça, Curitiba, v. 1, n. 2, p. $726-747$, jul./dez. 2016, p. 735 . "Trata-se
de um custo necessário, porém o legislador deve tentar fazer com que o ônus do tempo
seja partilhado de forma harmoniosa e justa entre as partes, evitando que apenas um delas
fique indevidamente sobrecarregada pelos efeitos temporais. (...) Se por um lado, não se
pode permitir que o tempo seja um aliado para aquele que não consegue apresentar em
juízo elementos que no mínimo causem dúvida razoável acerca do direito pleiteado em seu
desfavor, usando o processo apenas como ferramenta para postergar o cumprimento de
suas obrigações, por outro, também haverá momentos em que a demora processual será a
única forma de se alcançar a efetiva justiça." ${ }^{6}$ AMARAL, Guilherme Rizzo. Comentários às alterações do novo CPC. 2 ed. São Paulo: RT, 2016, p. 411. 
Possui a mesma natureza jurídica da tutela antecipada, tratando-se da mesma espécie de provimento, qual seja, fornecer, desde já (portanto, de forma provisória) o bem da vida perseguido pelo interessado. Consequentemente, ambas apresentam um caráter satisfativo, destinando-se ao mesmo fim, embora se utilizem de técnicas processuais diferentes.

Convêm distinguir, aqui, as tutelas jurisdicionais (tutela-fim) e técnicas processuais (tutela-meio). As primeiras dizem respeito à perseguição ou proteção ao direito material discutido no processo, estando intrinsecamente ligadas ao provimento jurisdicional perseguido (pedido) pelo interessado (tutela reparatória, inibitória, dentre outras). Por isso, serão elas finais e permanentes, protegidas pela imutabilidade da coisa julgada material. Já as segundas cumprem duas funções primordiais: a conservação do processo e a satisfação do interessado. Para a atividade conservativa, ter-se-á a técnica acautelatória; em relação à atividade satisfativa, há duas técnicas distintas: a tutela antecipada (tutela "meio urgente") e a tutela de evidência, a depender da existência ou não da urgência e do grau de probabilidade de existência do próprio direito material.

Essencialmente, o alto grau de probabilidade de deter o direito alegado (e, em consequência, de êxito na demanda) dispensa a ocorrência da urgência, ou seja, será concedida "independentemente da demonstração de perigo de dano ou de risco ao resultado útil do processo" (art. 311, caput, CPC/15). Como ressalta Costa, “(...) salta-se do plano da mera verossimilhança para o da quase certeza"7. Esse espírito de "quase certeza" e a exigência de prova documental pré-constituída aproximam a tutela de evidência do mandado de segurança, ao menos no que toca à liminar, eis que equivale ao "direito líquido e certo" exigido por este ${ }^{8}$. De todo modo, o interessado poderá utilizar uma ou outra (tutela antecipada ou tutela de evidência), ou mesmo ambas, para alcançar a proteção pretendida?

\footnotetext{
${ }^{7}$ COSTA, Eduardo José da Fonseca. Art. 311, In: STRECK, Lenio Luiz; NUNES, Dierle; CUNHA, Leonardo Carneiro da. Comentários ao código de processo civil. São Paulo: Saraiva, 2016, p. 448-455, p. 448.

${ }^{8}$ CÂMARA, Alexandre Freitas. O novo processo civil brasileiro. 3 ed. São Paulo: Atlas, 2017, p. 173. “Tem-se aí, então situação equivalente àquela do mandado de segurança, cuja concessão exige a demonstração de direito líquido e certo (assim compreendido aquele direito cujo fato constitutivo é demonstrável através de prova exclusivamente documental e pré-constituída)."

${ }^{9}$ KOEHLER, Frederico Augusto Leopoldino; MIRANDA, Gabriela Expósito Tenório. Conceituação e classificação da antecipação dos efeitos da tutela, da tutela cautelar e da tutela de

Resenha Eleitoral (Florianópolis), v. 24, n. 2, p. 65-80, 2020
} 


\section{Requisitos e hipóteses de cabimento da tutela de evidência}

Conforme o direito positivado, na exata redação do art. 311 do Código de Processo Civil "A tutela da evidência será concedida, independentemente da demonstração de perigo de dano ou de risco ao resultado útil do processo (...)". O dispositivo indica apenas o requisito negativo para a concessão (ausência do perigo na demora), não relacionando o que necessita ser demonstrado para a concessão.

Como tutela provisória que é, a probabilidade do direito deverá sempre se fazer presente. Esse é seu requisito positivo, que deverá ser provado pelo interessado no seu deferimento. As hipóteses (que serão vistas a seguir) materializam circunstâncias fáticas em que a probabilidade do direito se faz presente. Demonstrada qualquer daquelas, essa estará presente. Recorde-se, aqui, que subsunção dos fatos da vida às hipóteses legais trazem o alto grau da evidência do direito, a quase certeza, já acima referida.

As hipóteses de cabimento da tutela de evidência foram expressamente previstas nos incisos do art. 311 do CPC. A opção legislativa foi de estabelecer situações fáticas que, conforme o texto legal, constituem um direito evidente. Seu preenchimento ocorre pela subsunção do caso concreto ao texto legal. Logo, a evidência do direito, para fins de concessão da tutela, não é matéria a ser definida pela ciência do direito, mas, sim, pelo direito positivo.

De se adiantar que a hipótese prevista no inciso III do art. 311 do $\mathrm{CPC}^{10}$ não será aqui examinada, já que contempla situação fática claramente inaplicável no direito processual eleitoral ${ }^{11}$.

evidência. In: FREIRE, Alexandre; DANTAS, Bruno; NUNES, Dierle; et. al. Novas tendências do processo civil. v. 2. Salvador: Juspodivm, 2014, p. 605-618, p. 613. "Neste item demonstrar-se-á a ideia de que, além do juízo de simples verossimilhança, a técnica antecipatória, em muitas vezes, baseia-se também na urgência; noutros casos, todavia, o juízo de simples verossimilhança é suficiente. A classificação das tutelas em urgência e de evidência, tão em voga atualmente, muito por força do Novo CPC, cujo texto externa a segunda, só tem sentido se se estiver diante da técnica antecipatória. Na verdade, urgência e evidência são pressupostos, por vezes concorrentes, noutras vezes cumulativos, para o deferimento de tal técnica. A importância desse item, do ponto de vista metodológico, é, sem dúvida, manifesta."

10 "III - se tratar de pedido reipersecutório fundado em prova documental adequada do contrato de depósito, caso em que será decretada a ordem de entrega do objeto custodiado, sob cominação de multa".

11 TSE, Agravo Regimental no Recurso. Especial Eleitoral n. 803-62. 2012.6.26.0023, de São Paulo, rel. Min. Luiz Fux, j. em 30/11/2017. “Esclareço que a hipótese de cabimento 


\subsection{Ficar caracterizado o abuso do direito de defesa ou o mani- festo propósito protelatório da parte}

Ocorre nos casos em que o réu, tendo ciência de que não possui o direito que se discute, atua deliberadamente, nos momentos reservados ao exercício de sua defesa, para fazer com que o autor suporte o ônus do tempo do processo.

Deve haver o dolo processual ${ }^{12}$, caracterizado pela vontade emulativa de estender a marcha processual. Garante-se, portanto, o direito de defesa, que é fundamental e não pode ser afastado, mas se objetiva desestimular a conduta que arrasta a marcha processual.

Somados, o alto grau da probabilidade do direito do autor e a conduta protelatória do réu, permitem a concessão adiantada do bem jurídico pretendido na demanda ${ }^{13}$.

$\mathrm{Na}$ linha majoritária, diferencia-se o abuso do direito de defesa, que se identifica por meio de atos praticados durante o processo, do manifesto propósito protelatório, os atos praticados fora do processo ${ }^{14}$. Também, entende-se que a concessão da tutela antecipada não é incompatível com o sancionamento pela litigância de má-fé ${ }^{15}$.

\subsection{As alegações de fato puderem ser comprovadas apenas do- cumentalmente e houver tese firmada em julgamento de casos repetitivos ou em súmula vinculante}

A tutela de evidência prevista nesta hipótese se trata de técnica processual apta à satisfação provisória nos casos em que o requerente consiga (ou possa) comprovar a situação fática alegada por meio tão somente

inscrita no inciso III não tem aplicabilidade no âmbito desta Justiça Especializada, visto não ser matéria afeta à seara eleitoral."

${ }^{12}$ THEODORO JÚNIOR, 2017, p. 886. Contra: WANBIER, Luiz Rodrigues, Curso avançado de processo civil - vol 2. São Paulo: Revista dos Tribunais, 2016, p. 467.

${ }^{13}$ Enunciado n. 47 da I Jornada de Direito Processual Civil do CJF: "A probabilidade do direito constitui requisito para concessão da tutela da evidência fundada em abuso do direito de defesa ou em manifesto propósito protelatório da parte contrária."

${ }^{14}$ SÁ, Renato Montans de. Manual de Direito Processual Civil. 2 ed. São Paulo: Saraiva, 2016, p. 312.

${ }^{15}$ Ibdi., p. 314.

Resenha Eleitoral (Florianópolis), v. 24, n. 2, p. 65-80, 2020 
de documentos ${ }^{16}$, e a tese jurídica sustentada já tiver sido firmada em julgamento de casos repetitivos ou em súmula vinculante. Refere-se, de uma forma ou de outra, ao pretenso "sistema de precedentes"17.

Os requisitos do art. 311, inciso II, do CPC/15 são dois: a) a certeza sobre os fatos, por produção de prova exclusivamente documental; e b) a alta probabilidade sobre o direito alegado (ou de êxito), estampado em um pronunciamento judicial que justamente represente aquilo que seja o direito de uma determinada comunidade em determinado momento. Nesse particular, "não pode haver controvérsia, na jurisprudência, acerca da procedência do que se pede" $" 18$.

Para Costa, a utilização da jurisprudência e de precedentes para a concessão de liminares em geral gera uma economia de meios ${ }^{19}$. Analisa-se a liminar com menor esforço judicial, e sua reversão será improvável, pelo alinhamento justamente às deliberações anteriores da própria corte de revisão ${ }^{20}$.

Conforme dito, pela inaplicabilidade da hipótese do inciso III no direito eleitoral, passa-se diretamente a análise do próximo inciso.

\footnotetext{
${ }^{16}$ MACÊDO, Lucas Buril de. Antecipação da tutela por evidência e os precedentes obrigatórios. Revista de Processo, v. 242, p. 523-552, abr. 2015, p. 532. "A primeira exigência é de que se trate de situação fática de baixa complexidade probatória, que são aquelas possíveis de serem suficientemente provadas por meio de documentos."

${ }^{17}$ DOT'TI, Rogéria. Precedentes judiciais e antecipação: a tutela da evidência no novo CPC. Revista de direito da ADVOCEF, a. 11, n. 21, p. 59-75, nov. 2015, p. 67. "Tal hipótese procura unir, de um lado, a necessidade de acelerar a satisfação do direito provável da parte e, de outro, o sistema de respeito aos precedentes judiciais."

${ }^{18}$ MEDINA, José Miguel Garcia. Curso de direito processual civil moderno. 3 ed. São Paulo: RT, 2017, p. 508.

${ }^{19}$ COSTA, 2016, p. 449.

${ }^{20}$ Ainda que, descritivamente, tal situação possa ser observada no cotidiano forense, normativamente ela não se sustenta, porque não há facilitações hermenêuticas ou metodológicas no emprego de precedentes. Mais importante, há a responsabilidade política do juiz em resolver uma questão de forma correta, o que faz ruir análises simplistas ou o seguir irrefletido (ou com menos reflexão que a necessária) de um determinado precedente ou da jurisprudência majoritária das cortes de sobreposição.
} 


\subsection{A petição inicial for instruída com prova documental sufi- ciente dos fatos constitutivos do direito do autor, a que o réu não oponha prova capaz de gerar dúvida razoável}

A petição inicial instruída com prova suficiente consubstancia o alto grau de probabilidade do direito, requisito que, como já dissemos, deve se fazer presente para a concessão da tutela de evidência em todas as hipóteses.

Aqui, entretanto, o réu já apresentou resposta, que foi insuficiente para infirmar a demonstração documental dos fatos constitutivos realizada pelo autor ${ }^{21}$. O grau de probabilidade do direito do autor aumenta na mesma proporção da insubsistência dos argumentos e provas trazidos pelo réu.

Se a defesa insubsistente permite a concessão da tutela de evidência, também se autoriza no caso de revelia. Por óbvio, mesmo a defesa débil ainda é uma defesa, enquanto sua ausência é um nada, que proporciona maior segurança para a decisão provisória favorável ao autor.

Veja-se que ainda está se tratando de tutela de evidência, espécie de tutela provisória, em que a cognição é sumária. São casos em que embora evidente, o direito não é suficiente para uma decisão de mérito, sendo necessária a dilação probatória. Caso o juiz entenda estar o feito maduro, sem necessidade de produção de provas, deverá lançar mão do julgamento antecipado o mérito (arts. 355 e 356 do CPC) 22 , caso em que não haverá uma tutela provisória de evidência, mas sim uma tutela definitiva.

\section{Cabimento da tutela de evidência no direito processual eleitoral}

A legislação eleitoral específica não contempla o instituto da tutela de evidência. Sua aplicabilidade no direito processual eleitoral, no entanto, é certa, havendo diversas disposições expressas nesse sentido.

${ }^{21}$ COSTA, 2016, p. 452: “Trata-se de tutela provisória in inittio litis, mas necessariamente audiatur et altera pars. Afinal, é preciso saber se o réu logrará probatoriamente opor dúvida razoável à existência da pretensão de direito material afirmada na inicial."

22 "Art. 355. O juiz julgará antecipadamente o pedido, proferindo sentença com resolução de mérito, quando: I - não houver necessidade de produção de outras provas; II - o réu for revel, ocorrer o efeito previsto no art. 344 e não houver requerimento de prova, na forma do art. 349. Art. 356. O juiz decidirá parcialmente o mérito quando um ou mais dos pedidos formulados ou parcela deles: I - mostrar-se incontroverso; II - estiver em condições de imediato julgamento, nos termos do art. 355. (...)." 
O art. 15 do Código de Processo Civil determina expressamente a aplicação de suas disposições aos processos eleitorais, desde que ausentes normas que regulem esses processos ${ }^{23}$. Seguindo os parâmetros gerais das normas, essa aplicação será supletiva e subsidiária.

Exercitando seu poder regulamentar, o Tribunal Superior Eleitoral editou a Resolução n. 23.478, em 10 de maio de 2016, com objetivo de estabelecer "diretrizes gerais para a aplicação da Lei n. 13.105, de 16 de março de 2015 - Novo Código de Processo Civil -, no âmbito da Justiça Eleitoral”. Em seu art. 14, previu a forma de autuação da tutela provisória, tanto as antecedentes, no caput, quanto às incidentes, em seu parágrafo único ${ }^{24}$. Certo é que assim agindo, admitiu o cabimento desse instrumento no âmbito eleitoral.

Desde o início de vigência do CPC/2015, o Tribunal Regional Eleitoral de Santa Catarina ${ }^{25}$ e o TSE ${ }^{26}$, em seus precedentes, vem admitindo a figura da tutela de evidência.

23 "Art. 15. Na ausência de normas que regulem processos eleitorais, trabalhistas ou administrativos, as disposições deste Código lhes serão aplicadas supletiva e subsidiariamente." 24 “Art. 14. Os pedidos autônomos de tutela provisória serão autuados em classe própria. Parágrafo único. "Os pedidos apresentados de forma incidental em relação a feitos em tramitação serão encaminhados à autoridade judiciária competente, que determinará a sua juntada aos autos principais ou adotará as providências que entender cabíveis."

25 “TUTELA DE EVIDÊNCIA - ART. 301, I, DO CPC - REQUERIMENTO FORMULADO PELO MINISTÉRIO PÚBLICO ELEITORAL - REGISTRO DE CANDIDATURA INDEFERIDO POR INELEGIBILIDADE, CUJA INCIDÊNCIA É INCONTROVERSA, POIS DECORRE DE MERA INTERPRETAÇÃO DE DISPOSITIVOS DE LEI - PRECEDENTE DO TRESC - DEFERIMENTO - DETERMINAÇÃO DE APLICAÇÃO IMEDIATA DOS EFEITOS DO INDEFERIMENTO DO REQUERIMENTO DE REGISTRO DE CANDIDATURA - IMPEDIMENTO DE REALIZAR PROPAGANDA ELEITORAL E ATOS DE CAMPANHA - DETERMINAÇÃO DE RETIRADA DO NOME DA URNA ELETRÔNICA - INTIMAÇÃO DO PARTIDO DA PROIBIÇÃO DE VEICULAR PROPAGANDA ELEITORAL DO CANDIDATO E DE MOVIMENTAR RECURSOS PÚBLICOS EM BENEFÍCIO DA REFERIDACANDIDATURA" (Registro de Candidatura (11532) .. 0601183-52.2018.6.24.0000, rela. Juíza Luísa Hickel Gamba, j. em 17/9/2018). Na decisão dos embargos de declaração houve correção do erro material, substituindo-se a referência do art. “301, I, do CPC” pelo “art. 311, I, do CPC".

26 “ 1 . A tutela de evidência poderá ser concedida independentemente da existência de perigo de dano ou de risco ao útil resultado do processo. Todavia, a concessão dessa tutela provisória fica condicionada à demonstração de uma das situações plasmadas no art. 311 do CPC, que elenca rol taxativo das hipóteses de cabimento. (Recurso Especial n. 80.362, rel. Min. Luiz Fux, DJE 9/2/2018). 


\section{Casuística da tutela de evidência no direito processual eleitoral}

A aplicação do instituto na seara eleitoral é ampla, aplicando-se, virtualmente, a qualquer processo desde que observados os requisitos do art. 311 do CPC. Como expressa Cardoso, "no processo eleitoral poderá ser concedida a tutela da evidência em ações de perda de mandato eletivo, cassação de diploma, rejeição de contas (entre outras), dispensada a prova de urgência ${ }^{27 "}$.

$\mathrm{Na}$ prática, contudo, a tutela de evidência vem sendo utilizada de forma paulatina pelas Cortes Eleitorais, com parcimônia diante dos interesses que estão em conflito. Se, por um lado, espera-se que a Justiça Eleitoral cumpra seu papel regulador no tempo adequado, no outro, é democraticamente desejável que se garanta o acesso dos interessados ao sistema eleitoral, especialmente a possibilidade de serem escolhidos por meio de votação popular.

Com esse espírito, a tutela de evidência tem sido empregada notadamente em decisões que dizem respeito ao registro de candidaturas, já que esse procedimento demanda uma solução rápida, sob pena de obstar a possibilidade de ser votado a quem regularmente a possua, ou de permitir que pessoas que não preencham os requisitos para o exercício concorram ao pleito. Ambos os casos causam tumulto ao processo de escolha eleitoral, subvertendo a ordem democrática da escolha de governantes e legisladores.

$\mathrm{Na}$ análise da casuística, encontramos precedente do TRE-SC que, utilizando-se da hipótese do art. 311, inciso I, do CPC, concedeu tutela de evidência, para impedir candidato de realizar propaganda eleitoral e atos de campanha, além de retirar seu nome da urna eletrônica, em caso de inelegibilidade por conta de aposentação compulsória decorrente de decisão sancionatória já preclusa ${ }^{28}$. Na decisão de aclaratórios desse acórdão, consignou-se a justificação para a utilização da tutela de evidência, que se amoldaria como apropriada ao caso $^{29}$.

${ }^{27}$ CARDOSO, Oscar Valente. A tutela provisória do processo eleitoral no novo Código de Processo Civil. Resenha Eleitoral, Florianópolis, v. 20, n. 1, p. 196, jul. 2016.

${ }^{28}$ TRE-SC, Registro de Candidatura n. 0600753-03.2018.6.24.0000, de Florianópolis, rel. Juiz Cid Goulart Junior, j. em 12/8/2018.

${ }^{29}$ TRE-SC, Registro de Candidatura n. 0600753-03.2018.6.24.0000, de Florianópolis, rel. Juiz Cid Goulart Junior, j. em 12/8/2018. “Ocorre, porém, que a cautelar incidental deferida pelo Pleno não possui a natureza de 'tutela de urgência', mas, em verdade, de 'tutela de evidência', porquanto tem por fundamento a necessidade de evitar o uso abusivo do direito 
Igualmente, o mesmo tribunal concedeu a tutela de evidência para obstar registro de candidatura de ex-servidor público condenado à pena de demissão, sem que se tivesse sido suspensa ou anulada tal sanção ${ }^{30}$; e de condenado, com trânsito em julgado, por crimes contra a fé pública ${ }^{31}$. Já o TRE-RJ aplicou mesmo entendimento em caso de condenação com trânsito em julgado pelo crime de tráfico de drogas ${ }^{32}$.

Todos os casos trazidos trataram de situações consolidadas, que não poderiam, ou teriam remotas chances de ser alteradas até a decisão final (e, também com a ocorrência do próprio pleito). Tratam de insuperáveis causas de inelegibilidade, por condenação criminal transitada em julgado ou sanção administrativa em decisão já preclusa, ambas sem revisão ou declaração de nulidade. Descortinam-se esses casos concretos, portanto, como a "quase certeza" do direito, nos termos trazidos pelas lições doutrinárias.

A hipótese do inciso II do art. 311 do CPC apresentou pouca utilização, até o momento, diante da ausência de precedentes judiciais vinculativos voltados especificamente aos casos de competência da Justiça Eleitoral ${ }^{33}$. Por certo, conforme evoluam os julgamentos das matérias eleitorais, precedentes obrigatórios serão originados nesta seara, possibilitando a aplicabilidade dessa hipótese.

Já com a utilização do inciso IV do art. 311 do CPC, o TRE-PI concedeu tutela de evidência para possibilitar a diplomação de candidato a vereador eleito que apresentou, intempestivamente, documentos de sua prestação e contas ${ }^{34}$.

de defesa, bem como o manejo de recursos apenas para protelar a solução da controvérsia, nos termos do art. 311, I, do Código de Processo Civil."

30 TRE-SC, Registro de Candidatura n. 0600942-78.2018.6.24.0000, de Florianópolis, rel. Juiz Fernando Luz da Gama Lobo D’Eça, j. em 17/8/2018.

31 TRE-SC, Registro de Candidatura n. 0601183-52.2018.6.24.0000, de Florianópolis, rel. Juíza Luísa Hickel Gamba, j. em 17/8/2018.

32 TRE-RJ, Registro de Candidatura n. 060100107, do Rio de Janeiro, rel. Juiz Raphael Ferreira de Mattos, j. em 17/9/2018.

33 TSE, Agravo Regimental no Recurso Ordinário n. 0600433-23.2018.6.25.0000, rel. Min. Adhemar Gonzaga, j. em 2/10/2018. "Com efeito, afastadas as hipóteses alusivas ao pedido reipersecutório e à apresentação de prova suficiente com a exordial, obviamente inaplicáveis à espécie, destaco não haver tese firmada em julgamento de casos repetitivos ou em súmula vinculante acerca do tema vertido nos autos, institutos também estranhos ao processo de registro de candidatura."

34 TRE-PI, Ação Cautelar n 37620, de Gilbués, rel. Juíza Maria Célia Lima Lúcio, j. em $23 / 1 / 2017$. 
Novamente, a situação era consolidada. Os documentos comprobatórios das despesas já existiam, embora não tivessem sido juntados com a prestação de contas. Não havia, portanto, possibilidade de que as situações fáticas desaparecessem.

Sugerindo outra aplicação para a mesma hipótese, Pereira cita caso de ação para cassação de candidatura em que o requerido não apresente defesa apta a apresentar dúvida razoável ${ }^{35}$.

O que se sustenta, inclusive pela análise da casuística, é que a tutela de evidência deve ter vez no direito eleitoral, em casos de indeferimento de registro de candidatura, com concessão estrita aos casos em que não for possível, ou for muito difícil, a reversão da situação fática apresentada. São situações que apresentam uma insuperável e manifesta inelegibilidade, como os casos com condenação criminal já transitada em julgada ou sanções administrativas já alcançadas pela preclusão, ambas sem discussões judiciais aptas a alterarem a realidade encontrada (como no caso de ação rescisória, de nulidade de ato jurídico, etc.).

Nessas situações, em que a inelegibilidade está plenamente caracterizada, sem dúvida ou discussão de fato apta a possibilitar alteração da situação, não se demonstra razoável permitir a manutenção do registro provisório e dos atos decorrentes da candidatura, como prevê o art. 16-A, da Lei $9.504 / 97^{36}$. Age, assim, com alto grau de probabilidade, embora que ainda provisoriamente, para preservar o direito do cidadão-eleitor de não financiar, mediante destinação de propaganda eleitoral gratuita e de recur-

${ }^{35}$ PEREIRA, Luiz Fernando Casagrande. Cassação de Mandato, o Novo Efeito Suspensivo Automático do Código Eleitoral e a Tutela de Evidência do NCPC. Revista Jurídica da Procuradoria-Geral do Estado do Paraná, Curitiba, n. 7, 2016, p. 37-77. "A tutela de evidência, agora expressa no art. 311, é instrumento de distribuição mais equânime do ônus de demora do processo. Se o eleitor, extraordinariamente representado numa ação de cassação, apresenta um alto grau de verossimilhança de suas alegações, e o candidato requerido não apresenta defesa que gere dúvida razoável, o correto seria afastá-lo em tutela antecipada de evidência (art. 311, IV). Ora, se o NCPC, aplicável aqui (nenhuma dúvida) ao Direito Eleitoral, autoriza o afastamento antes da sentença (grau de verossimilhança alto), por que não com a sentença (grau de verossimilhança máximo)?”

36 "Art. 16-A. O candidato cujo registro esteja sub judice poderá efetuar todos os atos relativos à campanha eleitoral, inclusive utilizar o horário eleitoral gratuito no rádio e na televisão e ter seu nome mantido na urna eletrônica enquanto estiver sob essa condição, ficando a validade dos votos a ele atribuídos condicionada ao deferimento de seu registro por instância superior."

Resenha Eleitoral (Florianópolis), v. 24, n. 2, p. 65-80, 2020 
sos públicos, candidato cuja decisão de indeferimento não possui a mínima possibilidade de reversão.

De mesmo modo, cabe o deferimento da tutela de evidência para permitir a candidato que seja diplomado, em caso de inconsistência de documentos, que são apresentados posteriormente, e se referem a situações fática já ocorridas. Por lógica temporal, o que já ocorreu não pode ser mudado. São, portanto, também inalteráveis e consolidadas, podendo apenas ser representados no presente. A ausência de possibilidade de sua modificação concede o grau elevado exigível para a tutela de evidência.

\section{Conclusão}

Tempo e processo não são elementos contrapostos. Se o objetivo da jurisdição é apresentar uma resposta justa, alguma dilação temporal será necessária para a averiguação da situação de fato e, também, para que se possibilite o exercício dos direitos fundamentais como a ampla defesa e o contraditório. No entanto, a prática apresenta situações em que a probabilidade do direito se faz presente em tão elevado grau que a demora processual se apresenta injusta. Para redistribuir os ônus da demora processual, foi prevista pelo Código de Processo Civil a tutela de evidência.

Espécie de tutela provisória, a tutela de evidência possui quatro hipóteses de cabimento quando fundada no art. 311 do CPC. Dessas, apenas uma não guarda qualquer relação com o direito processual eleitoral, já que o inciso III do dispositivo trata de pedido reipersecutório fundado em contrato de depósito, claramente inaplicável à Justiça Especializada.

As demais hipóteses (incisos I, II e IV do art. 311 do CPC) são plenamente aplicáveis aos processos eleitorais, havendo disposição expressa sobre isso no CPC (art. 15), na legislação regulamentar proveniente do Tribunal Superior Eleitoral (Resolução n. 23.478, em 10 de maio de 2016), além de ampla aceitação jurisprudencial.

Nesse último tópico, deve-se frisar que as decisões do TSE proferidas após a entrada em vigor do CPC/15 não há uma sequer que vede a incidência do instituto na justiça especializada. Ao contrário, há o enfrentamento dos requisitos necessários, decidindo-se pela concessão ou indeferimento da medida, na presença ou ausência de seus pressupostos.

Nos precedentes da Justiça Especializada se encontram vários julgados, em Cortes Regionais e na Corte Superiora, concedendo a tutela de 
evidência para obstar o registro de candidato com inelegibilidades patentes e insuperável, como são os casos de condenação criminal com trânsito em julgado e aplicação de sanção administrativa já alcançada pela preclusão. Também se encontra caso de concessão para permitir a diplomação de candidato que entregou documentos comprobatórios de despesas extemporaneamente.

Em comum, todos os casos em que foi concedida a tutela de evidência apresentaram situações fáticas consolidadas, impossíveis de modificação, ou com chance de alteração altamente remota. Esse parece ser o ponto de equilíbrio dessa espécie de tutela provisória no direito processual eleitoral.

A restrição dos direitos eleitorais, e notadamente a participação na eleição, é cabível apenas em casos excepcionais, por ser matéria afeita aos direitos fundamentais. Igualmente, a disputa eleitoral realizada somente por pessoas que passaram por prévia habilitação, na forma da legislação, é garantia do cidadão-eleitor, e também não pode ser afastada. A resolução desse aparente impasse se dá na possibilidade de se adiantar os efeitos vindouros altamente prováveis da decisão.

A tutela de evidência no direito processual eleitoral fica reservada, portanto, para as demandas em que se apresente a "quase certeza" do direito em discussão, salvaguardando-se, assim, tanto os direitos individuais do cidadão-candidato quanto da coletividade.

\section{Referências}

AMARAL, Guilherme Rizzo. Comentários às alterações do novo CPC. 2 ed. São Paulo: RT, 2016.

CÂMARA, Alexandre Freitas. O novo processo civil brasileiro. 3 ed. São Paulo: Atlas, 2017.

CARDOSO, Oscar Valente. A tutela provisória do processo eleitoral no novo Código de Processo Civil. Resenha Eleitoral, Florianópolis, v. 20, n. 1, p. 196, jul. 2016.

COSTA, Eduardo José da Fonseca. Art. 311, In: STRECK, Lenio Luiz; NUNES, Dierle; CUNHA, Leonardo Carneiro da. Comentários ao código de processo civil. São Paulo: Saraiva, p. 448-455, 2016.

DOTTI, Rogéria. Precedentes judiciais e antecipação: a tutela da evidência no novo CPC. Revista de direito da ADVOCEF, a. 11, n. 21, p. 59-75, nov. 2015. 
FIALHO, Arthur Monteiro Lins; BONIFÁCIO, Artur Cortez. O efetivo acesso ao judiciário e o tempo processual sob a perspectiva da tutela de evidência. Revista de cidadania e acesso à justiça, Curitiba, v. 1, n. 2, p. 726-747, jul./dez. 2016.

KOEHLER, Frederico Augusto Leopoldino; MIRANDA, Gabriela Expósito Tenório. Conceituação e classificação da antecipação dos efeitos da tutela, da tutela cautelar e da tutela de evidência. In: FREIRE, Alexandre; DANTAS, Bruno; NUNES, Dierle; et. al. Novas tendências do processo civil. v. 2. Salvador: Juspodivm, 2014, p. 605-618.

MACÊDO, Lucas Buril de. Antecipação da tutela por evidência e os precedentes obrigatórios. Revista de Processo, v. 242, p. 523-552, abr. 2015.

MEDINA, José Miguel Garcia. Curso de direito processual civil moderno. 3 ed. São Paulo: RT, 2017.

PEREIRA, Luiz Fernando Casagrande. Cassação de Mandato, o Novo Efeito Suspensivo Automático do Código Eleitoral e a Tutela de Evidência do NCPC. Revista Jurídica da Procuradoria-Geral do Estado do Paraná, Curitiba, n. 7, p. 37-77, 2016.

THEODORO JÚNIOR, Humberto. Curso de Direito Processual Civil. 58 ed. Rio de Janeiro: Forense, 2017.

WANBIER, Luiz Rodrigues. Curso avançado de processo civil - vol 2. São Paulo: Revista dos Tribunais, 2016.

Fernando Vieira Luiz - Doutor em Direito (UFSC). Mestre em Direito (UNESA). LL.M. in U.S. Legal Studies (University of Connecticut School of Law - Honors). Juiz de Direito em Santa Catarina. Juiz Substituto do TRE-SC (2013-2015). Juiz Auxiliar do TSE (20182019). Juiz Instrutor no STJ (2019-2020). Membro do IBDP.

Rafael Covolan Pontin - Assessor Jurídico do Poder Judiciário de Santa Catarina. Especialista em Direito Penal e Processo Penal pela Escola do Ministério Público de Santa Catarina.

Marina de Oliveira de Vasconcellos Luiz - Advogada. Especialista em Direito Penal e Processo Penal pela Escola do Ministério Público de Santa Catarina. 